INJUSTICE AND RETALIATION

MINDFULNESS BUFFERS RETALIATORY RESPONSES TO INJUSTICE:

A REGULATORY APPROACH

\author{
ERIN C. LONG \\ University of North Carolina \\ Kenan-Flagler Business School \\ CB\#3490, McColl Bldg \\ Chapel Hill, NC 27599-3490 \\ Tel: (336) 339-2564 \\ Fax: (919) 962-4425 \\ email: Erin_Long@unc.edu \\ MICHAEL S. CHRISTIAN \\ University of North Carolina \\ Kenan-Flagler Business School \\ CB\#3490, McColl Bldg \\ Chapel Hill, NC 27599-3490 \\ Tel: (919) 962-2983 \\ Fax: (919) 962-4425 \\ email: Mike_Christian@unc.edu
}

Post-print version of Long, E. C., \& Christian, M. S. (2015). Mindfulness buffers retaliatory responses to injustice: A regulatory approach. Journal of Applied Psychology, 100(5), 14091422. doi:10.1037/apl0000019

(C)American Psychological Association, 2015. This paper is not the copy of record and may not exactly replicate the authoritative document published in the APA journal. The final article is available, upon publication, at: https://doi.org/10.1037/ap10000019. For use of the final article, please request permission there.

Author note: The authors would like to thank Jeff Edwards for his invaluable insight, feedback, and encouragement in all stages of this research. We would also like to acknowledge Noah Eisenkraft for his advice and support with data analysis. Finally, we thank Jennifer Fink and Virginia Stewart for their assistance with data collection, and appreciate the helpful suggestions and encouragement from Lisa Barnard and Michael Banker. 


\title{
Mindfulness buffers retaliatory responses to injustice: A regulatory approach
}

\begin{abstract}
We investigate the role of mindfulness as a regulatory factor by examining whether it mitigates the relationship between justice and retaliation. Drawing on theories of self-regulation, we integrate work on justice with emerging frameworks that identify mindfulness as an important work-related regulatory variable (Glomb, Duffy, Bono, \&Yang, 2011). Specifically, we identify the role of mindfulness as a buffer of the ruminative thoughts and negative emotions that link injustice to retaliation. We test mediated moderation hypotheses in two samples. In Sample 1, two behavioral measures of retaliation were assessed in an experiment that manipulated both injustice and mindfulness. In Sample 2, we generalize our model to the field, examining employee responses regarding experiences with workplace injustice and retaliation. Results of both studies converge to support the proposed mediated moderation model that mindfulness buffers the effect of injustice on rumination and negative emotions, thus reducing retaliation. Our findings contribute to the broader literatures on self-regulation, organizational justice, and retaliation.
\end{abstract}


"To be able to divorce themselves from what just happened that's inherent to them -- a referee's bad call, or an issue that goes on individually or against your opponent. You've got to be able to come back to your center and center yourself again.” - Phil Jackson, on mindfulness training with New York Knicks (Sports Illustrated, Oct, 2014).

Mindfulness, a psychological construct associated with non-judgmental attention and awareness of present-moment experiences, is of increasing interest in organizations (e.g., Dane, 2011; Glomb, Duffy, Bono, \&Yang, 2011). Emerging theoretical models of employee mindfulness suggest a self-regulatory function: employee mindfulness optimizes behavior at work by enhancing a set of processes that "form a series of pathways by which mindfulness and mindfulness-based practices lead to improved self-regulation and, ultimately, higher functioning" (Glomb, et al., 2011; p. 124). Despite emerging theory, little empirical work has focused on mindful self-regulation at work. We draw on the framework developed by Glomb and colleagues (2011) to argue that mindfulness is relevant when employees experience adverse events, helping to increase regulation over thoughts, emotions, and behaviors.

In particular, we argue that mindfulness reduces workplace retaliation, or volitional behavior intended to "even the score" for a perceived injustice. Retaliation is costly to organizations and their members, leading to a range of undesirable outcomes (e.g., Bradfield \& Aquino, 1999; Skarlicki \& Folger, 2005; Thau \& Mitchell, 2010), and is driven by dual regulatory processes_-"cold," instrumental cognitions, and "hot," affective reactions (Ambrose, Seabright, \& Schminke, 2002; Lee \& Allen, 2002). As this paper unfolds, we argue that mindfulness mitigates suboptimal reactions to injustice-ruminative thought and outward negative emotion-thereby reducing retaliation.

Our research contributes in the following ways. We are among the first to examine the regulatory role of mindfulness in organizational contexts. By introducing mindfulness as a malleable psychological factor that buffers reactions to adverse workplace events, we extend research on more stable factors - such as trait negative affect, job attitudes, and rule commitment - that reduce rumination, negative emotion, and retaliation at work (e.g., Skarlicki \& Rupp, 2010; Wang et al., 
2013). Finally, we extend work suggesting that emotional regulation mitigates suboptimal employee responses to mistreatment (Lian et al., 2014; Wang, Liao, Zhan, \& Shi, 2011) by examining a factor that optimizes both emotional and cognitive regulatory function at work.

\section{Mindfulness at Work}

Mindfulness is a state of consciousness that can be increased with meditative exercises (Hafenbrack, Kinias, \& Barsade, 2014; Kiken \& Shook, 2011) while also varying naturally from person-to-person (e.g., Brown \& Ryan, 2003). As Glomb and colleagues' (2011) model suggests, both forms — state and trait—enhance self-regulatory processes, enabling people to "stay in the moment," without evaluation or reaction (Glomb et al., 2011).

According to Glomb and colleagues (2011), two "core factors" are basic defining elements of mindfulness: (a) decoupling of the self from experience, and (b) decreased automaticity. Mindfulness increases attention to momentary events—even adverse ones—but these core factors enable optimal responding in two ways. First, decoupling reduces the tendency to "take things personally.” Events are observed from a meta-perspective whereby employees remain detached separating ego from experiences - rather than inferring self-relevance. Adverse stimuli are experienced without perceived meaning for self-worth, reducing self-protective psychological processes (Brown, Ryan, \& Creswell, 2007a; 2007b; Glomb et al., 2011). Second, reduced automaticity defuses tendencies to respond quickly and reactively to stimuli. Mindfulness reduces narrow, heuristic-based thought (Hafenbrack et al., 2014), leading employees to perceive a broader array of appropriate, autonomously regulated responses to adverse events (e.g., Glomb et al., 2011).

Glomb and colleagues (2011) also link mindfulness to "secondary processes": the observable self-regulatory processes that are proximal and relevant to work-related behavior. Specifically, mindfulness optimizes regulatory processes associated with work-relevant thoughts and emotions. Increases in mindfulness reduce self-oriented and automatic responses to adverse work events, observed as decreased cognitive rumination and negative emotion. As we argue next, Glomb and 
colleagues' mindful self-regulation framework can be integrated with dual-process models of justice to uncover the regulatory processes by which mindfulness will defuse reactions to injustice at work.

\section{Mindfulness as a Buffer of Responses to Injustice}

Dual-process conceptualizations of injustice emphasize the distinct contributions of both cognitive and emotional self-regulatory processes (Johnson \& Lord, 2010; Li et al., 2011; Liu, Luksyte, Zhou, Shi, \& Wang, 2014; Maas \& van den Bos, 2009; Skarlicki \& Rupp, 2010). van den Bos (2007) conceptually integrates the two, describing injustice as a "hot cognitive process...in which cognitive and affective determinants often work together to produce people's judgments of what they think is just or unjust" (p. 61). Because mindfulness "short circuits" cognitive and emotional reactions to negative events, it should be associated with more favorable responses to injustice by reducing rumination and negative emotions.

Rumination. Although extant research has identified the role of justice cognitions and counterfactual thinking in reactions to injustice (e.g., Adams, 1965; Tripp, Bies, \& Aquino, 2007; Folger, 1986), recent research recognizes that rumination, or recurrent thought and evaluation of a goal-disruptive event, is a key regulatory mechanism that leads to retaliation (e.g., Bies \& Tripp, 1996; Bies, Tripp, \& Kramer, 1997; Tripp \& Bies, 2010; Wang et al., 2013). Rumination is triggered by experiences that threaten self-related goals (i.e., preservation of a positive self-image), such as mistreatment at work (Wang et al., 2013). Experiencing injustice at work sparks event-related ruminative thoughts that include revenge ideations (Tripp \& Bies, 2010). Ruminative thoughts are repetitive, automatic cognitions that "harp" on negative events (Borders, Earleywine, \& Jajodia, 2010); they are intrusive and self-focused, and often linger until the discrepancy is resolved (Wang et al., 2013), narrowing an individual's perceived behavioral response repertoire (Borders et al., 2010).

Mindfulness should reduce rumination after an injustice because ruminative thoughts are both self-oriented and automatic. First, mindfulness enables decoupling, or detachment of the self from experiences including self-oriented cognitions (Glomb et al., 2011). Thoughts about an 
injustice will be viewed objectively rather than taken as evaluative information about the self. Second, mindfulness reduces automaticity, a defining feature of repetitive, intrusive cognitions like rumination. Together, the two core factors associated with mindfulness will short-circuit ruminative reactions to injustice. Indeed, mindfulness lessens individuals' preoccupation with past events by emphasizing present-centered attention (Brown \& Ryan, 2003; Ramel, Goldin, Carmona, \& McQuaid, 2004; Shapiro, Carlson, Astin, \& Freedman, 2006). In sum, we hypothesize:

Hypothesis 1. The effects of injustice on ruminative thought will be weaker for individuals high in mindfulness.

Negative Emotion. Injustice often results in negative emotions, which occur as part of an automatic, reactive process (e.g., van den Bos, 2007). Outward-focused negative emotions (e.g., anger, hostility, frustration) are common reactions to perceived unfairness because they adaptively fuel behavioral tendencies to "right a wrong" and reduce discrepancies between self-relevant expectations of fair versus actual treatment (Barclay, Skarlicki, \& Pugh, 2005; Wang et al., 2013). Indeed, the association between injustice and state negative affect is robust (Colquitt et al., 2013).

Mindfulness will reduce self-serving and automatic emotional reactions to injustice. First, by decoupling, mindful individuals will draw less self-relevant, goal-disruptive meaning from unfair events. Thus mindfulness will reduce self-protective and negative action-oriented emotional reactions following an injustice. Second, by reducing automaticity of emotion, mindfulness decreases negative emotional responses to adverse events (Brown et al., 2007a; Glomb et al., 2011; Wright, Day, \& Howells, 2009). Mindfulness is associated with improved down-regulation of negative emotion and up-regulation of positive emotions (Fredrickson, Cohn, Coffey, Pek, \& Finkel, 2008; Giluk, 2009; 2010; Siegel, 2010), and recent work has linked mindfulness to increased job satisfaction and reduced emotional exhaustion through enhanced affective regulation (Hulsheger, Alberts, Feinholdt, \& Lang, 2013). Further, neuroscientific research suggests that individuals high in trait mindfulness have enhanced neural circuitry in the prefrontal cortex, which is associated with 
improved emotion regulation in the limbic system (Farb et al., 2010; Farb, Anderson, \& Segal, 2012; Siegel, 2007). In sum, we hypothesize:

Hypothesis 2. The effect of injustice on outward-focused negative emotion will be weaker for individuals high in mindfulness.

\section{A Mediated Moderation Model of Mindfulness and Retaliation}

Although dual-process models of workplace fairness suggest that injustice leads to "cold" cognitions and "hot" affective responses (van Den bos, 2007), less work examines how these processes might simultaneously link to retaliation behavior. Cognitively, transgression-focused rumination motivates retribution (Bies \& Tripp, 1996; Bordia, Restubog, \& Tang, 2008; Bradfield \& Aquino, 1999). Repetitive cognitions sustain event saliency (Bordia et al., 2008) and transform action tendencies associated with provocation into aggressive behaviors (Denson et al., 2011). Injustice also leads to retaliation through negative emotional states (Barclay, et al., 2005; Colquitt et al., 2013; Fox, Spector, \& Miles, 2001), particularly for outward negative emotions that motivate discrepancyreducing actions (Barclay, et al., 2005; Gailliot \& Tice, 2008). Thus, both cognition and emotion underlie the injustice-retaliation relationship.

Based on Glomb and colleagues' (2011) model of mindful self-regulation, we hypothesize that when mindfulness is high, unfairness is less likely to elicit negative thoughts and emotions, consequently exerting less influence on retaliation. Through its core effects of decoupling and reduced automaticity, mindfulness inhibits suboptimal regulatory processes—-transgression-focused rumination and outward negative motions - that are proximal to retaliation behavior. Indeed, mindfulness leads individuals to consider a broader range of behavioral responses (Wright et al., 2009) and increased behavioral tolerance for negative events (Baer, 2003; Borders et al., 2010; Heppner et al., 2008). We therefore hypothesized mediated moderation, such that ruminative thought and outward-focused negative emotion partially mediate the relationship between injustice and retaliatory behaviors, and that these effects are moderated by mindfulness (see Figure 1). 
mindfulness.

Hypothesis $\mathbf{3} \mathbf{a}$ and $\mathbf{b}$. Mindfulness moderates the indirect effects of injustice on retributive theft (3a) and retributive performance evaluations (3b) through ruminative thought and outward-focused negative emotion, such that the indirect effects are weaker (vs. stronger) when mindfulness is higher (vs. lower).

\section{Sample One Method}

Sample. Participants were 117 undergraduate, graduate students, and university staff at a southeastern university, recruited via email and offered $\$ 12$ to take part in a relaxation study. Eight individuals who failed attention checks were removed from analyses. Of the 109 participants, 69 percent were female, 54.1 percent were Caucasian, and were $22.64(S D=8.01$ ) years old on average.

Procedure. We utilized a 2 (injustice, fair control) $\times 2$ (mindfulness, mind-wandering control) factorial design and randomly assigned participants to conditions. Two experimenters played roles simulating a work hierarchy (e.g., J. Christian, M. Christian, Garza, \& Ellis, 2012; Jones \& Skarlicki, 2005): a "research assistant," and a "supervisor." The supervisor (a) gave feedback and (b) paid participants.

Following Colquitt, Scott, Judge, \& Shaw (2006), participants sat at individual stations, where eleven expensive-looking pens were visible. The assistant instructed participants to choose a pen to use, adding that it be theirs-to-take home. They were then given five minutes to perform a difficult, six-page proofreading task. The assistant explained that the supervisor would evaluate their work on the task, give individual feedback, and reward adequate performance with a $\$ 3$ bonus.

Next, participants listened to either the (1) mindfulness, or the (2) control (mind-wandering) audio clip (Hafenbrack et al., 2014; Kiken and Shook, 2011) through sound-reducing headphones. Afterwards, injustice was manipulated as participants received either fair or unfair supervisor feedback regarding performance on the proofreading task. Participants were subsequently instructed to sit for 2 minutes, allowing time to experience any post-feedback ruminative thoughts and 
emotions. After the two minutes, an online survey containing manipulation checks and mediator measures was completed, followed by an anonymous evaluation of the supervisor's performance. Finally, the supervisor entered the room and stated "I know my assistant said you could keep a pen, but I would have to buy more for the remaining sessions, so I would appreciate it if you didn't take one” (Colquitt et al., 2006). The supervisor left, giving participants a chance to steal pens. All participants were debriefed and paid a total of $\$ 15$.

\section{Manipulations.}

Injustice manipulation. We manipulated global injustice, which involved manipulating distributive, procedural, and interactional justice simultaneously (Ambrose \& Schminke, 2009; J. Christian et al., 2012). Following Colquitt and colleagues' (2006) method, participants received feedback about the proofreading task that was either fair or unfair. Supervisor feedback, including the $\$ 3$ bonus payment, was given privately in a nearby room (see Table 1 for manipulation scripts).

Mindfulness manipulation. Participants listened to one of two 12-minute audio recordings adapted from Kiken and Shook (2011) and depicted in Table 2. The mindfulness recording informed participants that the exercise would help them become more "present-focused," increasing awareness of what was happening "in the moment." A four-minute instructional segment preceded an eight-minute practice period interspersed with three brief reminders at 2.5 -minute intervals. This type of manipulation has shown to effectively induce mindful states in novices (e.g, Hafenbrack et al., 2014; Kiken \& Shook, 2011). Participants in the control condition were given mind-wandering instructions, an induction that elicits baseline, wakeful states (e.g., Hafenbrack et al., 2014; Kiken \& Shook, 2011). This recording paralleled the structure of the mindfulness induction, with four minutes of instruction followed by eight minutes of practice.

\section{Measures.}

Unless otherwise indicated, participants rated responses using 5-point scales $(1=$ strongly disagree to $5=$ strongly agree) . 
Mindfulness manipulation check. Immediately following the audio clip, individuals rated their experience in the preceding minutes using two five-point scales: (a) 1 ("I thought about anything I wanted to" [control]) to 5 ("I focused on the present" [mindfulness]) and (b) 1 ("I let my mind wander freely" [control]) to 5 ("I was mindful of the present moment" [mindfulness]).

Justice manipulation check. Four items adapted from the Perceived Organizational Justice scale (Ambrose \& Schminke, 2009) assessed fairness: (a) “Overall, I was treated fairly in this experiment"; (b) "In general, the treatment I received here was fair"; (c) "It seems the way things worked in this experiment were not fair" (reversed); and (d) "For the most part, this experiment treated people fairly."

Retaliation intentions. To validate our focal behavioral measures of retaliation, we measured intent to retaliate (Jones \& Skarlicki, 2005), which was expected to positively correlate with the retaliation variables. We used four items: (a) "I would complain about my treatment"; (b) "I would recommend this study to my friends who are planning to participate in a study"; (c) "It is possible that participants would complain about their treatment"; and (d) "I am enthusiastic about volunteering for future research with this same experimenter.” Items (b) and (d) were reverse coded.

Ruminative thought. Four items adapted from the Anger Rumination Scale (ARS; Sukhodolsky, Golub, \& Cromwell, 2001) assessed post-feedback rumination: (a) "I thought about events that angered me for a long time"; (b) "I had difficulty forgiving people who hurt me"; (c) "I thought about the reasons people treated me badly"; and (d) "I re-enacted an anger episode in my mind after it had happened." Instructions were modified to assess momentary rumination by asking participants to report "the extent to which you had the following experiences during the study today."

State negative emotion. Three items from the Positive and Negative Affect Scale (PANAS; Watson, Clark, \& Tellegen, 1988) assessed outward-focused negative emotion post-feedback: hostile, irritable, and upset (cf. Barclay, et al., 2005), on a scale ( $1=$ not at all to $5=$ extremely). 
Retaliation. We used two behavioral indicators of retaliation. First, retributive theft behavior was measured with pen theft (Colquitt et al., 2006). Because the supervisor indicated that taking a pen would harm her (e.g., indicating that she needed to save them for the remainder of the sessions), keeping a pen reflected retaliation against the supervisor in the form of theft. Retaliation scores ranged from 0 to 3 , where 0 indicated that no pen was taken from the participant's desk and 3 was the maximum. Second, retributive performance evaluations were assessed using "confidential" participant ratings of the supervisor that were unrelated to actual performance (J. Christian et al., 2012; Jones \& Skarlicki, 2005). Efforts to thwart promotion are a measure of retaliation (J. Christian et al., 2012; Kremer \& Stephens, 1983), and thus participants were instructed that their ratings of the supervisor who gave them feedback would help determine whether she should be promoted to lab director. To ensure that the results were not influenced by actual performance, participants rated supervisor knowledge about the proofreading task, which could not differ across conditions because the script was held constant. A 5 -point scale was used $(1=$ knows nothing about the task, $5=$ knows everything about the task), and lower ratings reflect retaliatory behavior.

\section{Sample 1 Results}

Correlations, descriptive statistics, and reliabilities are reported in Table 3, and means in Table 4.

\section{Manipulation Checks and Validation of Dependent Variables.}

Injustice manipulation. Overall fairness was lower in the injustice condition $(M=2.86, S D$ $=.91)$ than in the fair condition $(M=4.39, S D=0.82), F(1,106)=85.86, p<.001, \eta^{2}=.45$.

Mindfulness manipulation. Mindfulness was higher in the mindful condition $(M=2.98$, $S D=1.04)$ than the control condition $(M=1.93, S D=.82), F(1,105)=32.92, p<.001, \eta^{2}=.24$.

Retaliation measures. Retaliation intention was related to theft $(r=.28)$ and performance evaluations $(r=-.46)$, suggesting that both behaviors were valid measures of retaliation.

\section{Tests of Hypotheses.}

Moderation hypotheses. Hypotheses 1 and 2 predicted that mindfulness would attenuate 
the effect of injustice on ruminative thought and negative emotion. Significant Injustice $\mathrm{x}$ Mindfulness interactions for ruminative thought $(\mathrm{B}=-.72, p<.05)$ and negative emotion $(\mathrm{B}=-.57$, $p<.01)$ are presented in Table 5. As shown in Table 4, the injustice-control condition reported increased rumination (all $t \mathrm{~s}>2.60$, all $p \mathrm{~s}<.05$ ) and negative emotion (all ts $>2.91$, all $\mathrm{ps}<.01$ ) relative to any other condition (see Figures 2 and 3). Thus, hypotheses 1 and 2 were supported. Mediated moderation hypotheses. Hypotheses $3 \mathrm{a}$ and $3 \mathrm{~b}$ predicted that mindfulness would attenuate the indirect effects of injustice through ruminative thought and negative emotion on retributive theft $(\mathrm{H} 3 \mathrm{a})$ and retributive performance evaluations (H3b). Support for hypotheses 1 and 2 meets the first condition for mediated moderation. Next, tests of the conditional indirect effects of injustice on retaliation were examined with simultaneous entry of ruminative thought and negative emotion ${ }^{1}$. Table 6 shows that the indirect effect through ruminative thought was not significant for the mindfulness condition (coefficient $=-.03, \mathrm{p}>.05)$, but was positive and significant for the control condition (coefficient $=.23, \mathrm{p}<.05)$. The indirect effect through negative emotion was not significant for the mindfulness condition (coefficient $=.18, \mathrm{p}>.05$ ), but was positive and significant for the control condition (coefficient $=.61, \mathrm{p}<.05$ ). Therefore, hypothesis 3a received full support. Table 7 shows the indirect effect through negative emotion was attenuated for participants in the mindfulness condition (coefficient $=-.11, \mathrm{p}<.05$ ) compared to the control condition $($ coefficient $=-.33, \mathrm{p}<.05)$. However, the indirect effect through ruminative thought was not significant at any level of mindfulness. Thus, hypothesis $3 \mathrm{~b}$ was partially supported.

\section{Sample Two Method}

We performed a constructive replication using a second sample in order to provide benefits that the laboratory cannot, such as demonstrating external validity with employed individuals representing an array of occupations where retaliatory behavior can occur. We demonstrate the relevance of our theorizing for untrained individuals given that the majority of workers in the United

\footnotetext{
${ }^{1}$ Because retributive theft is a count variable, Poisson regression analysis was used to test the conditional indirect effects for dual-mediators in a path model for hypothesis 3 a.
} 
States have never undergone mindfulness training, yet many people focus on the present as part of their baseline attentional patterns (Brown \& Ryan, 2003; Glomb et al., 2011).

Sample and Procedure. Participants were 270 employed individuals who responded to an online survey in exchange for payment of $\$ 1$. Participants were recruited through Amazon's Mechanical Turk which has ben argued to be a reliable data source (Buhrmester, Kwang, \& Gosling, 2011). Six individuals failed attention checks and were removed from analyses. Of the remaining 264 respondents, 53 percent of the sample members were female, 79.2 percent were Caucasian, and $36.47(S D=11.43)$ years old on average.

\section{Measures.}

Unless otherwise indicated, participants rated responses using 5-point scales $(1=$ strongly disagree to 5 = strongly agree).

Perceived unfairness. Global justice (Ambrose and Schminke; 2009) assessed perceptions of workplace unfairness.

Trait mindfulness. The Mindfulness Attention and Awareness Scale (MAAS; Brown \& Ryan, 2003) assessed trait mindfulness. Participants reported the frequency with which they experienced fifteen different items on a five-point scale $(1=$ almost never to $5=$ almost always $)$. Example items included, "I find it difficult to stay focused on what's happening in the present," and "I find myself preoccupied with the future or the past."

Ruminative thought. We used the full 20-item version of the ARS (Sukhodolsky, et al., 2001). Instructions referred to work-related events to reflect ruminative thoughts about workplace experiences. Example items include "When something makes me angry, I turn the matter over and over again in my mind," and "I thought about the reasons people treated me badly."

Outward-focused Anger. Outward-focused anger was assessed using the seven-item anger subscale from the Aggression Questionnaire (Buss \& Perry, 1992). Instructions were adapted to reflect anger at work. Example items included, "I have trouble controlling my temper," and "When 
I'm frustrated, I let my irritation show."

Retaliation. A 19-item reciprocal deviance measure (Bennett \& Robinson, 2000) was used to assess retaliation behavior. Instructions from this scale were adapted so that responses reflected retaliatory reactions to unfair workplace treatment by asking participants to indicate their agreement "that you have done any of the following in order to get back at the organization or someone you work with for treating you unfairly or harming you in some way." Example items included "Said something hurtful to someone at work," and "Falsified a receipt to get reimbursed for more money than you spent on business expenses.”

Control variables. We controlled for gender, age, and negative affect in light of research suggesting that these variables are associated with unethical or deviant behaviors at work (Berry, Ones, \& Sacket, 2007). Negative affect was assessed using 10 items from the Positive and Negative Affect Schedule (PANAS; Watson et al., 1988).

\section{Results}

Intercorrelations, descriptive statistics, and reliabilities are reported in Table 8.

\section{Tests of hypotheses.}

Hypotheses 1 and 2 predicted that mindfulness would attenuate the effect of injustice on ruminative thought and negative emotion. Table 9 shows a significant interaction between perceived unfairness and mindfulness on ruminative thought $(\mathrm{B}=-.14, \mathrm{p}<.05)$, as well as negative emotion $(B=-.20, p<.05)$. Simple slopes tests revealed that lower mindfulness was associated with higher rumination $(\mathrm{B}=.33, \mathrm{p}<.05)$ and higher mindfulness was associated with lower rumination $(\mathrm{B}=$ $.13, \mathrm{p}<.05)$ in response to unfair treatment at work (See Figure 4). Lower mindfulness was associated with increased anger in response to unfairness $(B=.27, \mathrm{p}<.05)$, while this effect was mitigated for individuals high in trait mindfulness $(\mathrm{B}=-.02, \mathrm{p}>.05)$ at work (See Figure 5). These results support Hypotheses 1 and 2.

Mediated moderation hypotheses. The first condition for mediated moderation was met 
by finding support for hypotheses 1 and 2. As shown in Table 10 the indirect effect through ruminative thought was not significant at high levels of mindfulness (coefficient $=.03, \mathrm{p}>.05$ ), but was positive and significant at low (coefficient $=.07, \mathrm{p}<.05)$ and mean $($ coefficient $=.05, \mathrm{p}<.05)$ levels. Also, the indirect effect through anger was not significant at high levels (coefficient $=-.01, \mathrm{p}$ $>$.05), but was positive and significant at low (coefficient $=.07, \mathrm{p}<.05)$ and mean (coefficient $=$ $.03, \mathrm{p}<.05)$ levels of mindfulness. These results support hypothesis $3 \mathrm{a}$ and $3 \mathrm{~b}$.

\section{Discussion}

The purpose of this research was to investigate the role of mindfulness as a self-regulatory factor that mitigates processes underlying the injustice-retaliation relationship. We first manipulated both injustice and mindfulness in a controlled experiment with behavioral dependent variables. We next tested whether our model generalizes to the field, examining natural variation in employee mindfulness. The results converged to suggest that mindfulness reduces retaliation by buffering suboptimal motivational mechanisms.

\section{Theoretical Implications}

Our study has several theoretical implications. First, we advance theories of mindfulness in organizations by examining its relationship with motivational factors. We move beyond the traditional focus of research identifying its beneficial effects on health, stress and well-being (for a review, see Chiesa \& Serretti, 2010) to test emerging conceptualizations of mindfulness as having positive self-regulatory and behavioral implications at work (e.g., Hafenbrack et al., 2014; Glomb et al., 2011). Models of self-regulation have proven useful in identifying psychological factors (e.g., emotion regulation-Lian et al., 2014; Wang et al., 2011; experiential versus rational processingSkarlicki \& Rupp, 2010) that mitigate reactions to negative experiences at work. By integrating mindful self-regulation theories with dual-process models we identified a set of cognitive and emotional factors that are buffered by mindfulness, reducing the indirect effect of injustice on retaliation. This model has implications for research on other forms of work-relevant self-regulation 
such as attentional resources (e.g., Kanfer \& Ackerman, 1989; Beal, Weiss, Barros, \& MacDermid, 2005), work engagement (e.g., M. Christian, Eisenkraft, \& Kapadia, 2014), and emotion regulation (e.g., Beal, Trougakos, Weiss, \& Green, 2006). For instance, Rupp and Spencer (2006) found that unfairness experiences are associated with emotional labor; our framework suggests that mindfulness might reduce this effect.

Second, this is the first study to hypothesize and test the role of mindfulness in the injusticeretaliation relationship by demonstrating that a trainable psychological mindset helps diffuse negative employee reactions. This has implications for our understanding of counterproductive behavior. While much of the extant research has focused on identification of exogenous antecedents, including unfairness (Fox et al., 2001; Greenberg 1990; Greenberg \& Alge, 1998), personal offenses (e.g., Aquino, Tripp, \& Bies, 2001), sleep deprivation (Barnes, Schaubroeck, Huth, \& Ghumman, 2011; M. Christian \& Ellis, 2011), and abusive supervision (e.g, Lian et al., 2014; Tepper, 2000), research is beginning to identify contextual and individual difference moderators (e.g., Colquitt et al., 2006; Lian et al., 2014; Mitchell \& Ambrose, 2007; Liu et al., 2014; Tepper, Henle, Lambert, Giacalone, \& Duffy, 2008; Welsh, Ellis, M. Christian, \& Mai, 2014). Still, unexplained variance remains in the relationship between justice and counterproductive behavior (Colquitt et al., 2006). We addressed this gap, and our results suggest that mindfulness could have beneficial effects on a range of undesirable behaviors in organizations. For example, psychological contract breach leads to deviance (Bordia et al., 2008), and our results suggest that mindfulness may moderate this effect.

Finally, our work contributes to the organizational justice literature in two ways. First, our findings add to the emerging evidence that reactions to injustice can be understood within the context of dual-process theories (e.g., van den Bos; Li et al., 2011; Liu et al., 2014). Second, we extend emerging research on justice and rumination (e.g., Tripp \& Bies, 2010; Wang et al., 2013). In doing so, we move beyond focusing on justice perceptions, counterfactual thinking, or relative 
comparisons as cognitive outcomes of injustice (e.g., Adams, 1965; Tripp et al., 2007; Folger, 1986).

\section{Practical Implications}

Undesirable perceived injustice is often unavoidable in organizations (e.g., company-wide lay-offs; choosing among multiple eligible employees for a single promotion). Our findings suggest new options for reducing retaliation at work. In addition to leader training in fairness principles (e.g., Greenberg, 2006; Skarlicki \& Latham, 1997), employers may benefit from more proactive strategies such as promoting employee mindfulness. This might be done by increasing education about mindfulness techniques, creating an organizational culture that recognizes the merits of mindfulness, or by conducting large-scale interventions.

Moreover, our findings suggest that mindfulness training may be a useful tool for managers mediating disputes among employees in conflict-resolution scenarios, and may truncate cycles of coworker retaliation. Our study suggests that this training is not initially difficult for novice meditators and that learning these skills is efficacious in the short-term, consistent with other recent accounts of brief, one-time inductions in novices (Friese, Messner, \& Schaffner, 2012; Hafenbrack, et al., 2014; Hesser, Molander, Jungermann, \& Andersson, 2013; Kiken \& Shook, 2011; Wenk-Sormaz, 2005). This helps to reinforce the practical appeal of mindfulness training for employers in search of more immediate and proximal interventions.

\section{Limitations and Future Directions}

Alongside its strengths, the current research had several limitations that future research may address. Consistent with previous work on retaliation (J. Christian et al., 2012; Jones \& Skarlicki, 2005; Kremer \& Stephens, 1983), the first sample prioritized internal validity and provided a strong test using an experimental design that maximized the "can it happen" question (see Ilgen, 1986). We created exchange relationships using incentives that parallel those in an actual job. We also measured retaliation behaviors that not only had real consequences for the target, but also correlated with behavioral intentions. Still, differences between our study and actual organizational settings may 
limit the external validity of the findings. To address this limitation, we obtained a second, crosssectional sample of employed adults. We examined natural variation in employee mindfulness, a more distal source of mindful states (Brown \& Ryan, 2003), which provided an additional test of our framework. Despite problems with common method variance associated wtih cross-sectional selfreport designs (McGrath, 1982; Pedhazur \& Schmelkin, 1991; Podsakoff, MacKenzie, Lee, \& Podsakoff, 2003), the compensatory design trade-offs of both studies helped triangulate our findings in ways that a single study could not. Still, future work might extend this research by implementing alternative, more in-depth field designs that capitalize on temporal separation and reduce common method concerns (e.g., pre-post field intervention, experience sampling methodology, etc.).

There are several other ways that research can build on our framework. We focused on retaliation responses to global injustice, however future studies may uncover possible independent effects of justice dimensions. While retaliatory behavior appears to be relatively equivocal across types of injustice (Ambrose et al., 2002), researchers might develop theoretical justification to examine mindfulness in the presence of specific dimensions. For example, researchers interested in interpersonal conflict might be concerned with interactional justice; whereas those examining reward structure might focus on distributive justice. Moreover, examining the impact of transgression severity might help us understand whether mindful states have an upper bound of effectiveness.

Also, the effects reported here might be applied to other precipitating factors for retaliation aside from top-down injustice. For example, coworkers often have conflicts among themselves or in teams, and may retaliate against each other. Future studies could explore the role of mindfulness as a mitigating factor when conflicts arise among peers. It is likely that employees in mindful states are more apt to harness potential benefits of conflict (e.g., Jehn, 1995) and respond more constructively.

Our framework may be applied more generally in future organizational studies on mindfulness and other behaviors that are guided by self-regulatory phenomena. For example, scholars might consider mindfulness in relation to employee safety. Mindfulness may encourage 
greater attentiveness to on-task behavior in dangerous situations and increase safety motivation, an important predictor of accidents and injuries (M. Christian, Bradley, Wallace, \& Burke, 2009). Given the importance of self-regulation to discretionary behaviors (e.g., M. Christian et al., 2014), mindfulness may also moderate the effects of constructs such as work engagement and self-control on citizenship and withdrawal behavior.

Future research might also examine the impact of mindfulness on proactive workplace outcomes. Moving beyond mindfulness as a factor that mitigates undesirable employee reactions and behaviors, researchers should consider that mindful states might promote positive psychological processes and behaviors. Bradfield and Aquino (1999) argue that identifying factors that discourage vengeful behavior is important, but that organizational research should also focus on how to better promote forgiveness at work. Thus, investigating possible effects of mindfulness on outcomes like forgiveness is an important future direction. Moreover, emerging research indicates that mindfulness strengthens the saliency of long-term goals and values, promoting persistent, goal-striving behavior (Brown et al., 2007a; 2007b; Shapiro et al., 2006). Our research supports the association between mindfulness and goal-congruent behavior, even under adverse conditions. Alternatively, some have theorized that the beneficial outcomes of mindfulness may be limited under certain conditions (e.g., Dane, 2011). While our framework and findings support the enhancing effects of mindfulness, future research might address this theoretical tension.

Finally, our framework considers the dual impact of cognitive and emotional mechanisms underlying the injustice-retaliation relationship. It is possible that the two processing modes operate sequentially or interact, rather than operating simultaneously as modeled in the current study. Although additional analyses did not reveal an interactive effect of the two mediators, future studies could consider a possible exacerbating relationship or investigate their temporal sequence. For example, Wang and colleagues (2013) found that service employee rumination about customer mistreatment led to increased negative mood the following day. 
Our research focuses specifically on the role of employee mindfulness as a regulatory buffer for the association between organizational justice and retaliation, however this study has broader implications for organizational research. Our hope is that scholars expand our current understanding of workplace behavior by integrating work on mindfulness and its regulatory functions. 


\section{References}

Adams, J. S. (1965). Inequity in social exchange. In L. Berkowitz (Ed.), Advances in experimental social psychology: Vol. 2 (pp. 267-299). New York: Academic Press.

Ambrose, M. L., \& Schminke, M. (2009). The role of overall justice judgments in organizational justice research: A test of mediation. Journal of Applied Psychology, 94, 491-500.

Ambrose, M. L., Seabright, M. A., \& Schminke, M. (2002). Sabotage in the workplace: The role of organizational injustice. Organizational Behavior and Human Decision Processes, 89, 947-965.

Aquino, K., Tripp, T. M., \& Bies, R. J. (2001). How employees respond to personal offence: The effects of blame attribution, victim status, and offender status on revenge and reconciliation in the workplace. Journal of Applied Psychology, 86(1), 52-59.

Baer, R. A. (2003). Mindfulness training as a clinical intervention: A conceptual and empirical review. Clinical Psychology: Science and Practice, 10, 125-143.

Barclay, L. J., Skarlicki, D. P., \& Pugh, S. D. (2005). Exploring the role of emotions in injustice perceptions and retaliation. Journal of Applied Psychology, 90, 629-643.

Barnes, C. M., Schaubroeck, J., Huth, M., \& Ghumman, S. (2011). Lack of sleep and unethical conduct. Organizational Behavior and Human Decision Processes, 115(2), 169-180.

Beal, D. J., Trougakos, J. P., Weiss, H. M., \& Green, S. G. (2006). Episodic processes in emotional labor: perceptions of affective delivery and regulation strategies. Journal of Applied Psychology, 91(5), 1053.

Beal, D. J., Weiss, H. M., Barros, E., \& MacDermid, S. M. (2005). An episodic process model of affective influences on performance. Journal of Applied Psychology, 90(6), 1054.

Bennett, R. J., \& Robinson, S. L. (2000). Development of a measure of workplace deviance. Journal of Applied Psychology, 85(3), 349-360.

Berry, C. M., Ones, D. S., \& Sackett, P. R. (2007). Interpersonal deviance, organizational deviance, 
and their common correlates: a review and meta-analysis. Journal of Applied Psychology, 92(2), 410.

Bies, R. J., \& Tripp, T. M. (1996). Beyond distrust: "Getting even" and the need for revenge. In R. M. Kramer \& T. R. Tyler (Eds.), Trust in organizations: Frontiers of theory and research, (pp. 246-2 60). Thousand Oaks, CA: Sage Publications, Inc.

Bies, R. J., Tripp, T. M., \& Kramer, R. M. 1997. At the breaking point: Cognitive and social dynamics of revenge in organizations. In R. Giacalone \& J. Greenberg (Eds.), Antisocial behavior in organizations, pp. 18-36. Thousand Oaks, CA: Sage.

Borders, A., Earleywine, M., \& Jajodia, A. (2010). Could mindfulness decrease anger, hostility, and aggression by decreasing rumination? Aggressive Behavior, 36(1), 28-44.

Bordia, P., Restubog, S. L. D., \& Tang, R. L. (2008). When employees strike back: Investigating mediating mechanisms between psychological contract breach and workplace deviance. Journal of Applied Psychology, 93(5), 1104-1117.

Bradfield, M., \& Aquino, K. (1999). The effects of blame attributions and offender likableness on forgiveness and revenge in the workplace. Journal of Management, 25(5), 607-631.

Brown, K. W., \& Ryan, R. M. (2003). The benefits of being present: Mindfulness and its role in psychological well-being. Journal of Personality and Social Psychology, 84, 822-848.

Brown, K. W., Ryan, R. M., \& Creswell, J. D. (2007a). Addressing fundamental questions about mindfulness. Psychological Inquiry, 18(4), 272-281.

Brown, K. W., Ryan, R. M., \& Creswell, J. D. (2007b). Mindfulness: Theoretical foundations and evidence for its salutary effects. Psychological Inquiry, 18(4), 211-237.

Buhrmester, M., Kwang, T., \& Gosling, S. D. (2011). Amazon's Mechanical Turk a new source of inexpensive, yet high-quality, data?. Perspectives on Psychological Science, 6(1), 3-5.

Buss, A. H., \& Perry, M. (1992). The aggression questionnaire. Journal of personality and social psychology, 63(3), 452. 
Chiesa, A. \& Serretti, A. (2010). A systematic review of neurobiological and clinical features of mindfulness meditations. Psychological Medicine: A Journal of Research in Psychiatry and the Allied Sciences, 40, 1239-1252.

Christian, M. S., Bradley, J. C., Wallace, J. C., \& Burke, M. J. (2009). Workplace safety: a meta analysis of the roles of person and situation factors. Journal of Applied Psychology, 94(5), 1103 1127.

Christian, J. S., Christian, M. S., Garza, A. S., \& Ellis, A. P. J. (2012). Examining retaliatory responses to justice violations and recovery attempts in teams. Journal of Applied Psychology, 97, 12181232.

Christian, M. S., Eisenkraft, N., \& Kapadia, C. (in press). Dynamic associations between somatic complaints, human energy, and discretionary behaviors: Experiences with pain fluctuations at work. Administrative Science Quarterly.

Christian, M. S., \& Ellis, A. P. (2011). Examining the effects of sleep deprivation on workplace deviance: A self-regulatory perspective. Academy of Management Journal, 54(5), 913-934.

Colquitt, J. A., Scott, B. A., Judge, T. A., \& Shaw, J. C. (2006). Justice and personality: Using integrative theories to derive moderators of justice effects. Organizational Behavior and Human Decision Processes, 100, 110-127.

Colquitt, J. A., Scott, B. A., Rodell, J. B., Long, D. M., Zapata, C. P., Conlon, D. E., \& Wesson, M. J. (2013). Justice at the millennium, a decade later: A meta-analytic test of social exchange and affect-based perspectives. Journal of Applied Psychology, 98, 199-236.

Dane, E. (2011). Paying attention to mindfulness and its effects on task performance in the workplace. Journal of Management, 37, 997-1018.

Denson, T. F., Pedersen, W. C., Friese, M., Hahm, A., \& Roberts, L. (2011). Understanding impulsive aggression: Angry rumination and reduced self-control capacity are mechanisms 
underlying the provocation-aggression relationship. Personality and Social Psychology Bulletin, 37(6), 850-862.

Farb, N. A. S., Anderson, A. K., Mayberg, H., Bean, J. McKeon, D., \& Segal, Z. V. (2010). Minding one's emotions: Mindfulness training alters the neural expression of sadness. Emotion, 10(1), 25-33.

Farb, N. A . S., Anderson, A. K., \& Segal, Z. V. (2012). The mindful brain and emotion regulation in mood disorders. Canadian Journal of Psychiatry, 57(2), 70-77.

Folger, R. (1986). Rethinking equity theory: A referent cognitions model. In H.W. Bierhoff, R.I., Cohen, \& J. Greenberg (Eds.), Justice in social relations (pp. 145-162). New York: Plenum Press.

Fox, S., Spector, P. E., \& Miles, D. (2001). Counterproductive work behavior (CWB) in response to job stressors and organizational justice: Some mediator and moderator tests for autonomy and emotions. Journal of Vocational Behavior, 59, 291-309.

Fredrickson, B. L., Cohn, M. A., Coffey, K. A., Pek, J., \& Finkel, S. M. (2008). Open hearts build lives: Positive emotions, induced through loving-kindness meditation, build consequential personal resources. Journal of Personality and Social Psychology, 95(5), 1045-1062.

Friese, M., Messner, C., \& Schaffner, Y. (2012). Mindfulness meditation counteracts self-control depletion. Consciousness and Cognition, 21(2), 1016-1022.

Gailliot, M. T., \& Tice, D. M. (2008). Emotion regulation and impulse control: People succumb to their impulses in order to feel better. In K.D. Vohs, R. F. Buameister, \& G. Loewenstein (Eds.), Do emotions help or hurt decisionmaking?: A bedgefoxian perspective (pp. 203-216). New York, NY: Russell Sage Foundation.

Giluk, T. L. (2009). Mindfulness, Big Five personality, and affect: A meta-analysis. Personality and Individual Differences, 47, 805-811.

Giluk, T. L. (2010). Mindfulness-based stress reduction: Facilitating work outcomes through 
experienced affect and high-quality relationships. Doctoral dissertation. Available at Iowa Research Online. http://ir.uiowa.edu/etd/674

Glomb, T. M., Duffy, M. K., Bono, J. E., \& Yang, T. (2011). Mindfulness at work. Research in Personnel and Human Resources Management, 30, 115-157.

Greenberg, J. (1990). Employee theft as a reaction to underpayment inequity: The hidden cost of pay cuts. Journal of Applied Psychology, 75(5), 561-568.

Greenberg, J. (2006). Losing sleep over organizational injustice: Attenuating insomniac reactions to underpayment inequity with supervisory training in interactional justice. Journal of Applied Psychology, 91(1), 58-69.

Greenberg, J. \& Alge, B. (1998). Aggressive reactions to workplace injustice. In R. W. Griffin, O'Leary-Kelly, \& J. Collins (Eds.), Dysfunctional behavior in organizations: Vol 1. Violent behaviors in organizations (pp. 119-145). Greenwich, CT: JAI.

Hafenbrack, A. C., Kinias, Z., \& Barsade, S. G. (2014). Debiasing the mind through meditation: Mindfulness and the sunk-cost bias. Psychological Science, 25(2), 369-376.

Heppner, W. L., Kernis, M. H., Lakey, C. E., Campbell, W. K., Goldman, B. M., Davis, P. J., \& Cascio, E. V. (2008). Mindfulness as a means of reducing aggressive behavior: Dispositional and situational evidence. Aggressive Behavior, 34(5), 486-496.

Hesser, H., Molander, P., Jungermann, M., \& Andersson, G. (2013). Costs of suppressing emotional sound and countereffects of a mindfulness induction: An experimental analog of tinnitus impact. PLoS ONE, 8(5), e64540.

Hulsheger, U. R., Alberts, H. J. E. M., Feinholdt, A., \& Lang, J. W. B. (2013). Benefits of mindfulness at work: The role of mindfulness in emotion regulation, emotional exhaustion, and job satisfaction. Journal of Applied Psychology, 98(2), 310-325.

Ilgen, D. (1986). Laboratory research, a question of when, not if. In E. Locke (Ed.), Generalizing from lab to field settings, 257-267. Lexington, MA: Heath. 
Jehn, K. A. (1995). A multimethod examination of the benefits and detriments of intragroup conflict. Administrative Science Quarterly, 40(2), 256-282.

Johnson, R. E., \& Lord, R. G. (2010). Implicit effects of justice on self-identity. Journal of Applied Psychology, 95(4), 681-695.

Jones, D. A., \& Skarlicki, D. P. (2005). The effects of overhearing peers discuss an authority's fairness reputation on reactions to subsequent treatment. Journal of Applied Psychology, 90, 363372.

Kanfer, R., \& Ackerman, P. L. (1989). Motivation and cognitive abilities: An integrative/aptitude treatment interaction approach to skill acquisition. Journal of applied psychology, 74(4), 657.

Kiken, L. G., \& Shook, N. J. (2011). Looking up: Mindfulness increases positive judgments and reduces negativity bias. Social Psychology and Personality Science, 2, 425-431.

Kremer, J. F., \& Stephens, L. (1983). Attributions and arousal as mediators of mitigation's effect on retaliation. Journal of Personality and Social Psychology, 45, 335-343.

Lee, K., \& Allen, N. J. (2002). Organizational citizenship behavior and workplace deviance: the role of affect and cognitions. Journal of Applied Psychology, 87, 131-142.

Lian, H., Brown, D. J., Ferris, D. L., Liang, L. H., Keeping, L. M., \& Morrison, R. (2014). Abusive supervision and retaliation: A self-control framework. Academy of Management Journal, 57(1), 116-139.

Li, A., Evans, J., Christian, M. S., Gilliland, S. W., Kausel, E. E., \& Stein, J. H. (2009). The effects of managerial regulatory fit priming on reactions to explanations. Organizational Behavior and Human Decision Processes, 115, 268-282.

Liu, S., Luksyte, A., Zhou, L., Shi, J., \& Wang, M. (2014). Overqualification and counterproductive work behaviors: Examining a moderated mediation model. Journal of Organizational Behavior. Maas, M., \& van den Bos, K. (2009). An affective-experiential perspective on reactions to fair and 
unfair events: Individual differences in affect intensity moderated by experiential mindsets. Journal of Experimental Social Psychology, 45(4), 667-675.

Maloy, B. (October 13, 2014). Knicks are undergoing mindfulness training before the season. Sports Illustrated. Retrieved from http://www.si.com/extra-mustard/2014/10/13/new-york-knicksphil-jackson-mindfulness-training.

McGrath, J. E. (1982). Dilemmatics: The study of research choices and dilemmas. In J. E. McGrath, J. Martin, \& R. A. Kulka (Eds.), Judgment Calls In Research (pp. 69-102). Beverly Hills, CA: Sage Publications.

Mitchell, M. S., \& Ambrose, M. L. (2007). Abusive supervision and workplace deviance and the moderating effects of negative reciprocity beliefs. Journal of Applied Psychology, 92(4), 1159.

Pedhazur, E. J., \& Schmelkin, L. P. (1991). Measurement, design, and analysis: An integrated approach. Psychology Press.

Podsakoff, P. M., MacKenzie, S. B., Lee, J., \& Podsakoff, N. P. (2003). Common method biases in behavioral research: A critical review of the literature and recommended remedies. Journal of Applied Psychology, 88, 879-903.

Ramel, W., Goldin, P. R., Carmona, P. E., \& McQuaid, J. R. (2004). The effects of mindfulness meditation on cognitive processes and affect in patients with past depression. Cognitive Therapy and Research, 28, 433-455.

Rupp, D. E., \& Spencer, S. (2006). When customers lash out: the effects of customer interactional injustice on emotional labor and the mediating role of discrete emotions. Journal of Applied Psychology, 91(4), 971.

Shapiro, S. L., Carlson, L. E., Astin, J.A., \& Freedman, B. (2006). Mechanisms of mindfulness. Journal of Clinical Psychology, 62, 373-386.

Siegel, D. J. (2007). Mindfulness training and neural integration: Differentiation of distinct streams 
of awareness and the cultivation of well-being. Social Cognitive and Affective Neuroscience (SCAN), 2, 259-263.

Siegel, R. D. (2010). The mindful solution: Everyday practices for everyday problems. New York, NY: Guilford Press.

Skarlicki, D. P., \& Folger, R. (1997). Retaliation in the workplace: The roles of distributive, procedural, and interactional justice. Journal of Applied Psychology, 82, 434-443.

Skarlicki, D. P., \& Folger, R. (2005). Broadening our understanding of organizational retaliatory behavior. In R. W. Griffin \& A. M. O’Leary- Kelly (Eds.), The dark side of organizational behavior (pp. 373-402). San Francisco, CA: Jossey-Bass.

Skarlicki, D. P., \& Latham, G. P. (1997). Leadership training in organizational justice to increase citizenship behavior within a labor union: A replication. Personnel Psychology, 50, 617-633.

Skarlicki, D. P., \& Rupp, D. E. (2010). Dual-processing and organizational justice: The role of rational versus experiential processing in third-party reactions to workplace mistreatment. Journal of Applied Psychology, 95(5), 944-952.

Sukhodolsky, D. G., Golub, A., \& Cromwell, E. N. (2001). Development and validation of the anger rumination scale. Personality and Individual Differences, 31, 689-700.

Tepper, B. J. (2000). Consequences of abusive supervision. Academy of management journal, 43(2), 178190.

Tepper, B. J., Henle, C. A., Lambert, L., Giacalone, R. A., \& Duffy, M. K. (2008). Abusive supervision and subordinates' organization deviance. Journal Of Applied Psychology, 93(4), 721 732.

Thau, S., \& Mitchell, M. S. (2010). Self-gain or self-regulation impairment? Tests of competing explanations of the supervisor abuse and employee deviance relationship through perceptions of distributive justice. Journal of Applied Psychology, 95, 1009-1031.

Tripp, T. M., \& Bies, R. J. (2010). "Righteous” Anger and Revenge in the Workplace: The Fantasies, 
the Feuds, the Forgiveness. In International handbook of anger (pp. 413-431). Springer New York.

Tripp, T. M., Bies, R. J., \& Aquino, K. (2007). A vigilante model of justice: Revenge, reconciliation, forgiveness, and avoidance. Social Justice Research, 20(1), 10-34.

van den Bos, K. (2007). Hot cognition and social justice judgments: The combined influence of cognitive and affective factors on the justice judgment process. In D. De Cremer (Ed.), Advances in the psychology of justice and affect (pp. 59-82). Charlotte, NC: Information Age Publishing, Inc.

Wang, M., Liao, H., Zhan, Y., \& Shi, J. (2011). Daily customer mistreatment and employee sabotage against customers: Examining emotion and resource perspectives. Academy of Management Journal, 54, 312-334.

Wang, M., Liu, S., Liao, H., Gong, Y., Kammeyer-Mueller, J., \& Shi, J. (2013). Can't get it out of my mind: Employee rumination after customer mistreatment and negative mood in the next morning. Journal of Applied Psychology, 98, 989-1004.

Watson, D., Clark, L. A., \& Tellegen, A. (1988). Development and validation of brief measures of positive and negative affect: The PANAS scales. Journal of Personality and Social Psychology, 54(6), 1063-1070.

Welsh, D. T., Ellis, A. P., Christian, M. S., \& Mai, K. M. (2014). Building a self-regulatory model of sleep deprivation and deception: The role of caffeine and social influence. Journal of Applied Psychology, 99(6), 1268-1277.

Wenk-Sormaz, H. (2005). Meditation can reduce habitual responding. Alternative Therapies in Health and Medicine, 11, 32-58.

Wright, S., Day, A., \& Howells, K. (2009). Mindfulness and the treatment of anger problems. Aggression and Violent Behavior, 14(5), 396-401. 
Table 1

Justice Manipulation Scripts (adapted from Colquitt et al., 2006)

\begin{tabular}{|l|l|}
\hline \multicolumn{1}{|c|}{ Injustice } & \multicolumn{1}{c|}{ Control (fair) } \\
\hline "I quickly glanced at your work on the proofreading task, \\
$\begin{array}{l}\text { and it's pretty obvious that you did not put very much } \\
\text { effort into this task (PJ). I know you guys only participate } \\
\text { in these studies for the money, but I don't care whether } \\
\text { you get paid (IJ). I'm not giving you the extra three bucks } \\
\text { (DJ)." }\end{array}$ & $\begin{array}{l}\text { participate today-I know people around here are really } \\
\text { busy, and we appreciate you putting in the effort (IJ). I } \\
\text { carefully read through your work on this difficult } \\
\text { proofreading task and can see you put a lot of effort into it } \\
\text { (PJ). So based on your effort and performance on this task, } \\
\text { I'm going to give you an extra \$3 (DJ). }\end{array}$ \\
\end{tabular}

Note: $\mathrm{PJ}=$ procedural justice; $\mathrm{IJ}=$ interactional justice; $\mathrm{DJ}=$ distributive justice. 
Table 2

Mindfulness Manipulation Scripts (adapted from Kiken and Shook, 2011)

\begin{tabular}{|c|c|c|}
\hline & Mindfulness & Control (mind-wandering) \\
\hline Instructions & $\begin{array}{l}\text { For four minutes, participants were instructed to } \\
\text { anchor attention to their breathing, to maintain a } \\
\text { sense of curiosity about momentary thoughts and } \\
\text { feelings without judgment, and to refocus their } \\
\text { attention on the present moment by attending to the } \\
\text { breath cycle if their thoughts wandered. }\end{array}$ & $\begin{array}{l}\text { For four minutes, participants were instructed to } \\
\text { think about anything that came to mind from the } \\
\text { past, present, or future. }\end{array}$ \\
\hline Reminders & $\begin{array}{l}\text { During the 8-minute practice segment, participants } \\
\text { received the following brief reminders: (1) "Gently } \\
\text { maintain attention on your breathing, being with } \\
\text { each breath in for its full duration and each breath } \\
\text { out for its full duration," (2) "If your mind wanders, } \\
\text { acknowledge that it has wandered to reconnect to } \\
\text { the present, and gently shift your attention back to } \\
\text { noticing the feeling of each breath," (3) "Let } \\
\text { yourself become more familiar with the process of } \\
\text { this experience." }\end{array}$ & $\begin{array}{l}\text { During the 8-minute practice segment, participants } \\
\text { received the following brief reminders: (1) } \\
\text { "Remember, this is time for your mind to wander } \\
\text { freely," (2) "As a reminder, you don't have to or even } \\
\text { want to think about just one thing; think about as } \\
\text { many different things as you want," (3) "Don't focus } \\
\text { too hard on anything. Think freely." }\end{array}$ \\
\hline
\end{tabular}


Table 3

Means, Standard Deviations, and Correlations among V ariables (Sample 1)

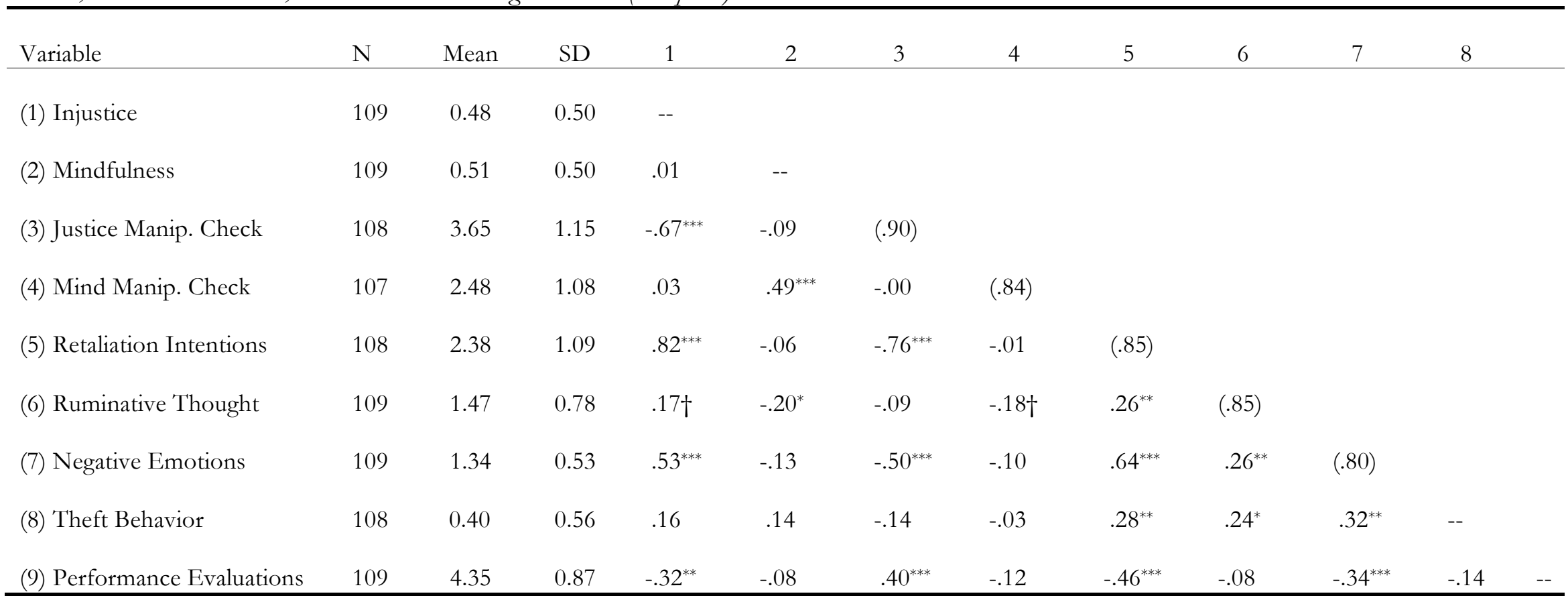

Note. Listwise deletion used for missing data. Reliabilities reported on the (diagonal). Injustice is coded as $0=$ Fair

Condition, 1 = Injustice Condition. Mindfulness is coded as $0=$ Control Condition, $1=$ Mindfulness Condition.

$\dagger \mathrm{p}<.10,{ }^{*} p<.05,{ }^{* *} p<.01,{ }^{* * *} p<.001$. 
Table 4

Means and Standard Deviations by Condition (Sample 1)

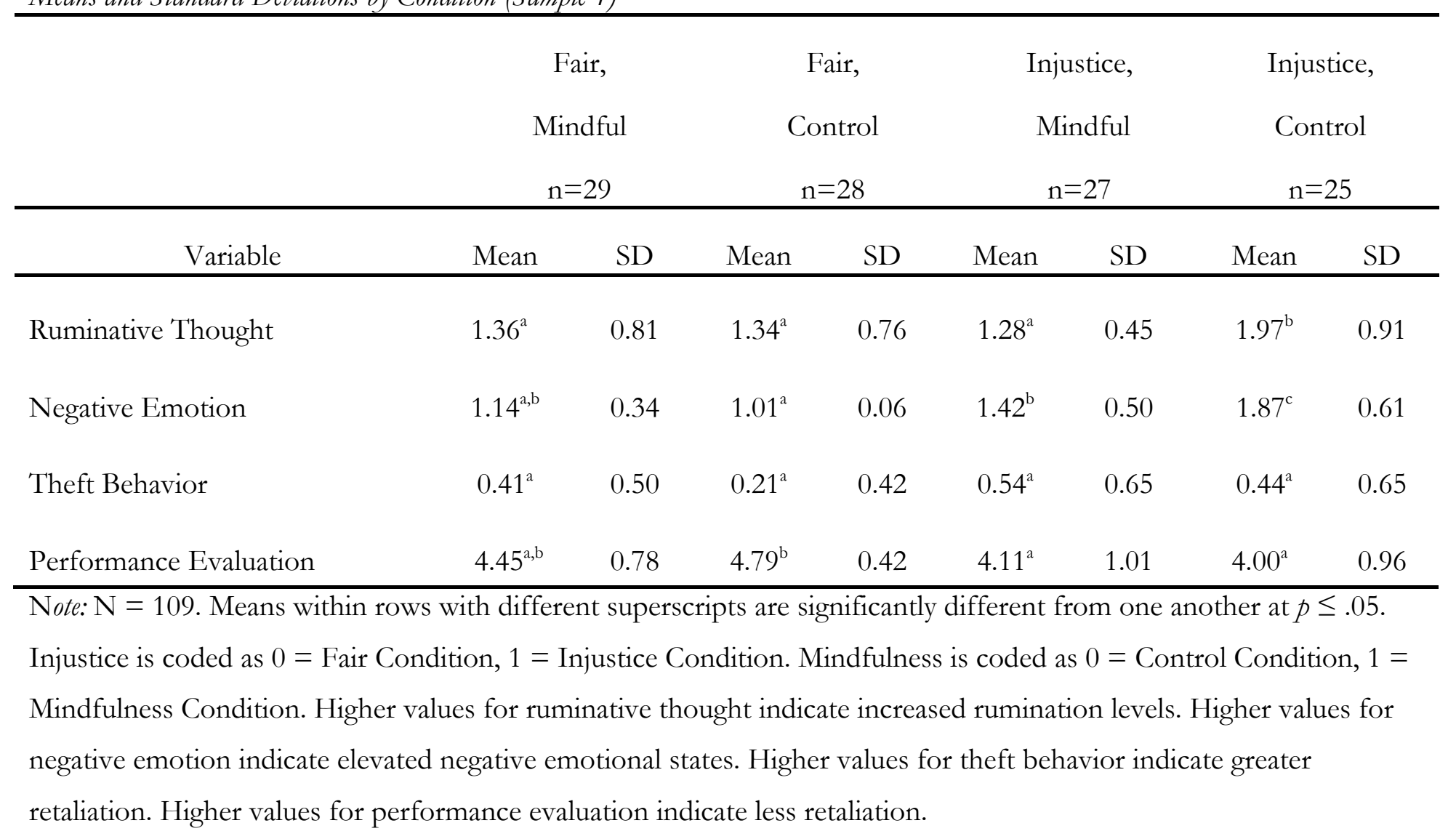


Table 5

Coefficient Estimates for the Moderated Mediation Model for Dual-Process Mediators as Dependent Variables (Sample 1)

\begin{tabular}{|c|c|c|c|c|c|c|c|c|c|c|c|c|}
\hline \multirow[b]{3}{*}{ Variable } & \multicolumn{6}{|c|}{ Ruminative Thought } & \multicolumn{6}{|c|}{ Negative Emotion } \\
\hline & \multicolumn{3}{|c|}{ Step 1} & \multicolumn{3}{|c|}{ Step 2} & \multicolumn{3}{|c|}{ Step 1} & \multicolumn{3}{|c|}{ Step 2} \\
\hline & $B$ & SE & $t$ & $B$ & SE & $t$ & $B$ & $S E$ & $t$ & $B$ & SE & $t$ \\
\hline Constant & 1.48 & .07 & $20.18^{* * *}$ & 1.48 & .07 & $20.70^{* * *}$ & 1.34 & .04 & $31.48^{* * *}$ & 1.35 & .04 & $33.17^{* * *}$ \\
\hline Injustice & .26 & .15 & $1.80^{\dagger}$ & .27 & .14 & $1.86^{\dagger}$ & .56 & .09 & $6.56^{* * *}$ & .56 & .08 & $6.93^{* * *}$ \\
\hline Mindfulness & -.32 & .15 & $-2.17^{*}$ & -.32 & .14 & $-2.23^{*}$ & -.15 & .09 & $-1.72^{\dagger}$ & -.15 & .08 & $-1.82^{\dagger}$ \\
\hline Injustice x Mindfulness & & & & -.72 & .29 & $-2.50^{*}$ & & & & -.57 & .16 & $-3.53^{* *}$ \\
\hline$R^{2}$ & & $.26^{*}$ & & & $.35^{* *}$ & & & $.55^{* * *}$ & & & $.61^{* * *}$ & \\
\hline$\Delta R^{2}$ & & & & & $.05^{*}$ & & & & & & $.07^{* *}$ & \\
\hline
\end{tabular}


Table 6

Results for Conditional Indirect Effects on Theft (Sample 1)

$\underline{95 \% \mathrm{CI}}$

Indirect Effect $S E$

LL

UL

Conditional indirect effects: Ruminative Thought

Mindfulness

$-.03$

.07

$-.154$

.099

Mind Wandering

.23

.09

.048

.416

Conditional indirect effects: Negative Emotion

\begin{tabular}{lllll} 
Mindfulness & .18 & .11 & -.033 & .401 \\
Mind Wandering & .61 & .19 & .241 & .970 \\
\hline
\end{tabular}

Note. $\mathrm{N}=108$. Listwise deletion used for missing data. $\mathrm{CI}=$ confidence interval; $\mathrm{LL}=$ lower limit; UL= upper limit.

Unstandardized regression coefficients are reported. Bootstrap sample size 1,000. 
Table 7

Results for Conditional Indirect Effects on Performance Evaluations (Sample 1)

$95 \%$ CI

Indirect Effect $S E$

LL UL

Conditional indirect effects: Ruminative Thought

$\begin{array}{lcccc}\text { Mindfulness } & -.00 & .02 & -.054 & .029 \\ \text { Mind Wandering } & .01 & .07 & -.114 & .187 \\ \text { nditional indirect effects: Negative Emotion } & & & & \\ \text { Mindfulness } & -.11 & .08 & -.333 & -.007 \\ \text { Mind Wandering } & -.33 & .16 & -.674 & -.020\end{array}$

Note. $\mathrm{N}=109 . \mathrm{CI}=$ confidence interval; $\mathrm{LL}=$ lower limit; $\mathrm{UL}=$ upper limit. Unstandardized regression coefficients are reported. Bootstrap sample size 1,000 . 
Table 8

Means, Standard Deviations, and Correlations among Variables (Sample 2)

\begin{tabular}{|c|c|c|c|c|c|c|c|c|c|c|c|}
\hline Variable & $\mathrm{N}$ & Mean & SD & 1 & 2 & 3 & 4 & 5 & 6 & 7 & \\
\hline (1) Perceived Unfairness & 259 & 2.18 & 1.00 & $(.94)$ & & & & & & & \\
\hline (2) Trait Mindfulness & 257 & 3.71 & 0.73 & $-.26^{* * *}$ & $(.91)$ & & & & & & \\
\hline (3) Ruminative Thought & 256 & 2.08 & 0.82 & $.45^{* * *}$ & $-.40^{* * *}$ & $(.95)$ & & & & & \\
\hline (4) Anger & 259 & 1.86 & 0.78 & $.32^{* * *}$ & $-.41^{* * *}$ & $.66^{* * *}$ & $(.85)$ & & & & \\
\hline (5) Retaliation & 257 & 1.68 & 0.72 & $.32^{* * *}$ & $-.46^{* * *}$ & $.53^{* * *}$ & $.51^{* * *}$ & $(.93)$ & & & \\
\hline (6) Negative Affect & 263 & 1.70 & 0.77 & $.35^{* * *}$ & $-.48^{* * *}$ & $.50^{* * *}$ & $.49^{* * *}$ & $.42^{* * *}$ & $(.93)$ & & \\
\hline (7) Gender ${ }^{a}$ & 264 & 0.53 & 0.50 & -.05 & -.05 & .03 & .04 & $-.13^{*}$ & .02 & -- & \\
\hline (8) Age & 264 & 36.47 & 11.43 & -.06 & .08 & $-.14^{*}$ & $-.16^{* *}$ & $-.12^{*}$ & $-.21^{* *}$ & .05 & -- \\
\hline
\end{tabular}

Note. Listwise deletion used for missing data. Reliabilities reported on the diagonal.

${ }^{a}$ Gender coded as $0=$ Male, $1=$ Female.

${ }^{*} p<.05,{ }^{* *} p<.01,{ }^{* * *} p<.001$. 
Table 9

Coefficient Estimates for the Moderated Mediation Model for Dual-Process Mediators as Dependent Variables (Sample 2)

\begin{tabular}{|c|c|c|c|c|c|c|c|c|c|}
\hline & \multicolumn{9}{|c|}{ Ruminative Thought } \\
\hline & \multicolumn{3}{|c|}{ Step 1} & \multicolumn{3}{|c|}{ Step 2} & \multicolumn{3}{|c|}{ Step 3} \\
\hline Variable & $B$ & SE & $t$ & $B$ & SE & $t$ & $B$ & SE & $t$ \\
\hline Constant & 1.30 & .21 & $6.29^{* * *}$ & 1.65 & .20 & $8.11^{* * *}$ & 1.63 & .20 & $8.10^{* * *}$ \\
\hline Age & -.004 & .004 & -.98 & -.004 & .004 & -1.12 & -.004 & .004 & -1.17 \\
\hline Gender & .04 & .09 & .47 & .05 & .09 & .52 & .07 & .09 & .75 \\
\hline Negative Affect & .52 & .06 & $8.65^{* * *}$ & .33 & .07 & $4.96^{* * *}$ & .32 & .07 & $4.85^{* * *}$ \\
\hline Unfairness & & & & .24 & .05 & $5.10^{* * *}$ & .23 & .05 & $5.07^{* * *}$ \\
\hline Trait Mindfulness & & & & -.20 & .07 & $-2.91^{* *}$ & -.22 & .07 & $-3.29^{* *}$ \\
\hline Unfairness x Mindfulness & & & & & & & -.14 & .06 & $-2.22^{*}$ \\
\hline$R^{2}$ & & $.26^{* * *}$ & & & $.36^{* * *}$ & & & $.37^{* * *}$ & \\
\hline$\Delta R^{2}$ & & & & & $.10^{* * *}$ & & & $.01^{*}$ & \\
\hline
\end{tabular}

Note. $N=245$. Listwise deletion used for missing data. Unstandardized regression coefficients are reported. All predictors were centered prior to analysis.

a Gender coded as $0=$ Male, $1=$ Female.

${ }^{\dagger} \mathrm{p}<.10,{ }^{*} p<.05,{ }^{* *} p<.01,{ }^{* * *} p<.001$. 
Table 9 (continued)

Coefficient Estimates for the Moderated Mediation Model for Dual-Process Mediators as Dependent Variables (Sample 2)

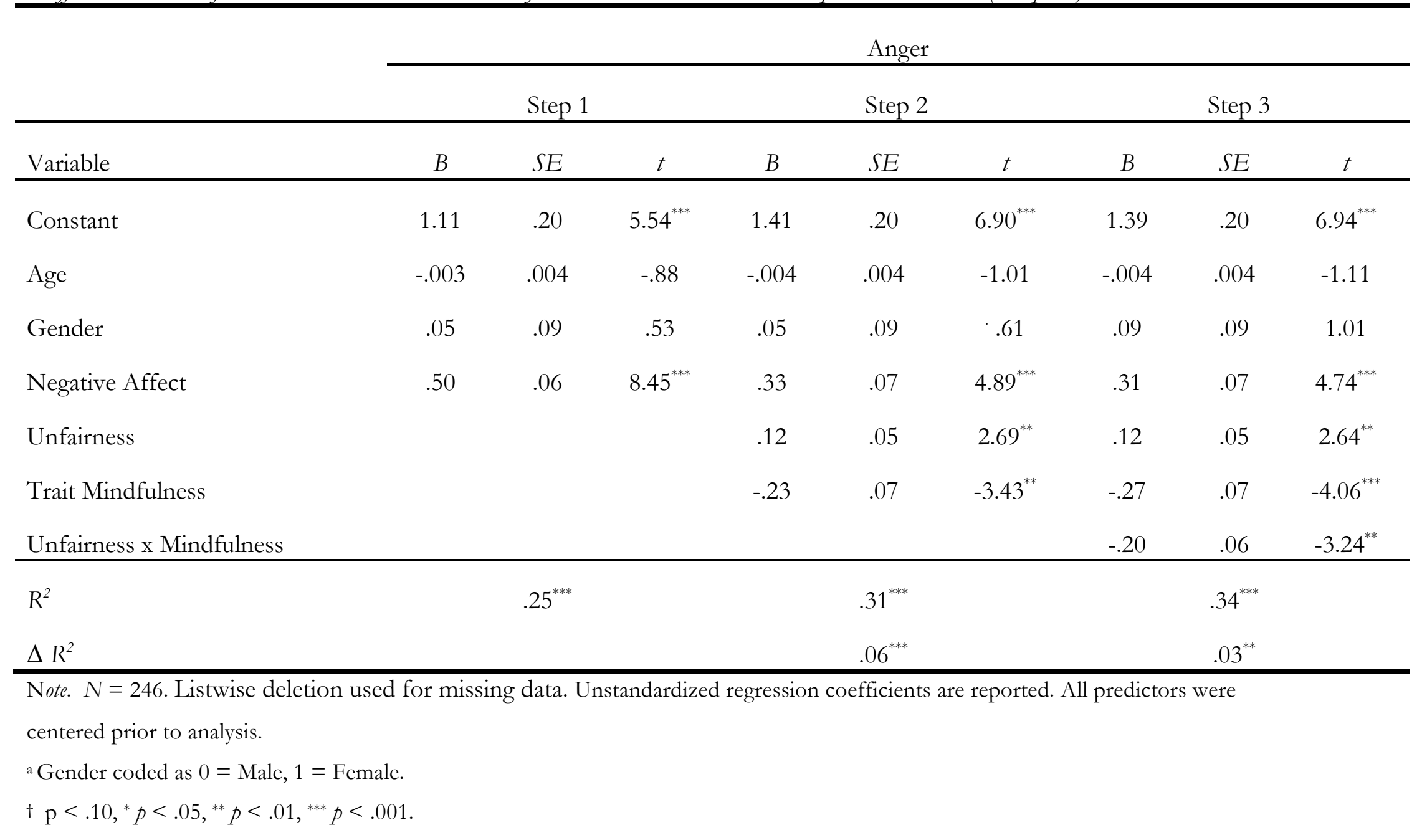


Table 10

Results for Conditional Indirect Effects on Retaliation (Sample 2)

\begin{tabular}{|c|c|c|c|c|c|}
\hline \multirow[b]{2}{*}{ Variable } & \multirow[b]{2}{*}{ Mindfulness } & \multirow[b]{2}{*}{ Indirect Effect } & \multirow[b]{2}{*}{ SE } & \multicolumn{2}{|c|}{$95 \% \mathrm{CI}$} \\
\hline & & & & LL & $\mathrm{UL}$ \\
\hline \multicolumn{6}{|c|}{ Conditional Indirect Effects: Ruminative Thought } \\
\hline Low Mindfulness (-1 SD) & -.75 & .07 & .03 & .021 & .139 \\
\hline Average Mindfulness & -.02 & .05 & .02 & .013 & .094 \\
\hline High Mindfulness (+1 SD) & .71 & .03 & .02 & -.002 & .070 \\
\hline \multicolumn{6}{|c|}{ Conditional Indirect Effects: Anger } \\
\hline Low Mindfulness (-1 SD) & -.75 & .07 & .03 & .027 & .145 \\
\hline Average Mindfulness & -.02 & .03 & .02 & .007 & .078 \\
\hline High Mindfulness (+1 SD) & .71 & -.01 & .02 & -.047 & .024 \\
\hline
\end{tabular}

Note. $\mathrm{N}=$ 235. Listwise deletion used for missing data. $\mathrm{CI}=$ confidence interval; $\mathrm{LL}=$ lower limit; UL= upper limit.

Unstandardized regression coefficients are reported. Bootstrap sample size 1,000. Tests of indirect effects for each mediator are reported at three levels of the moderator: 1) 1 standard deviation below the mean, 2) the mean, and 3) 1 standard deviation above the mean. 
Figure 1: Hypothesized model

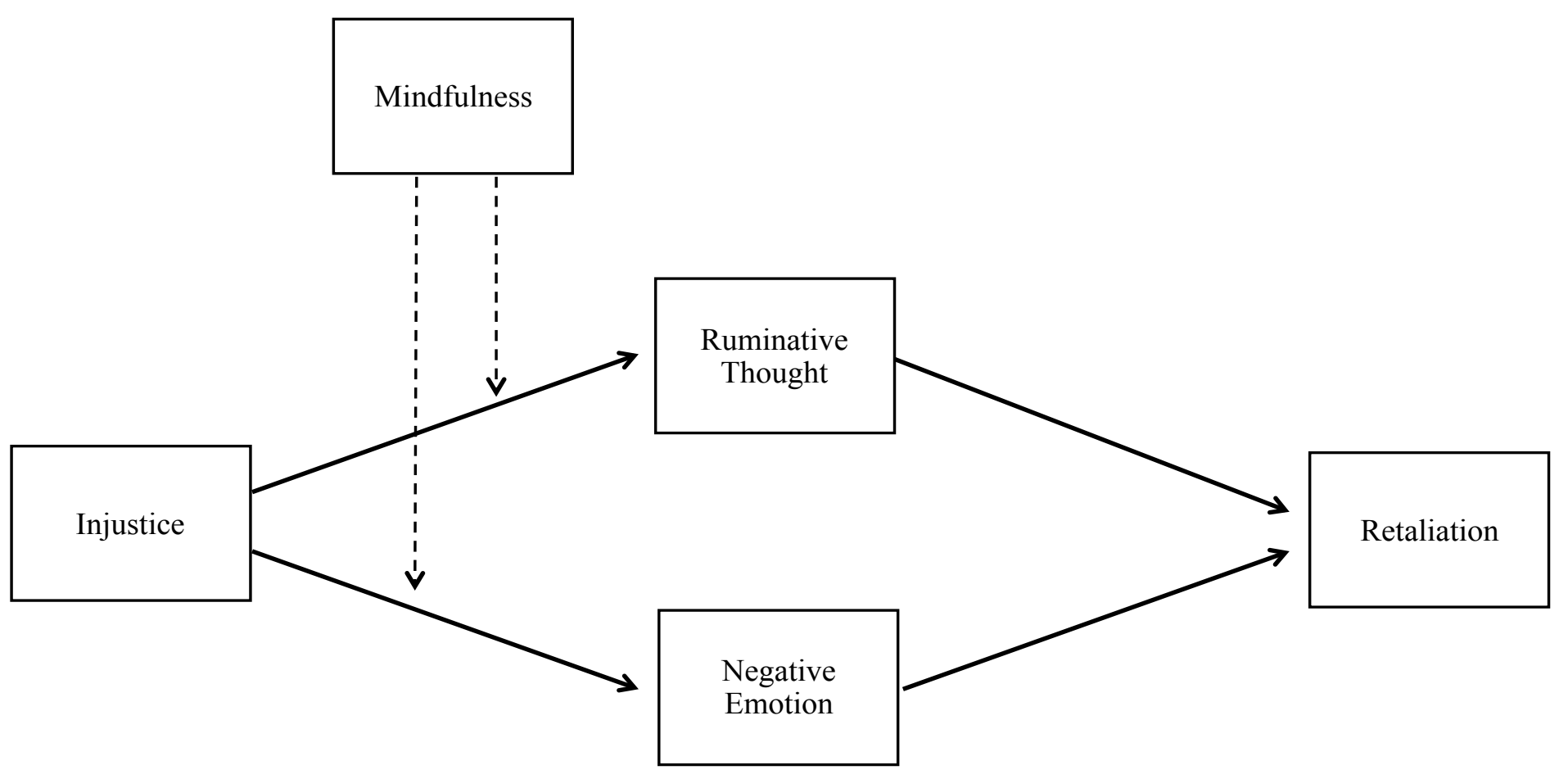


Figure 2: Interactive effects of injustice and mindfulness on ruminative thought (Sample 1)

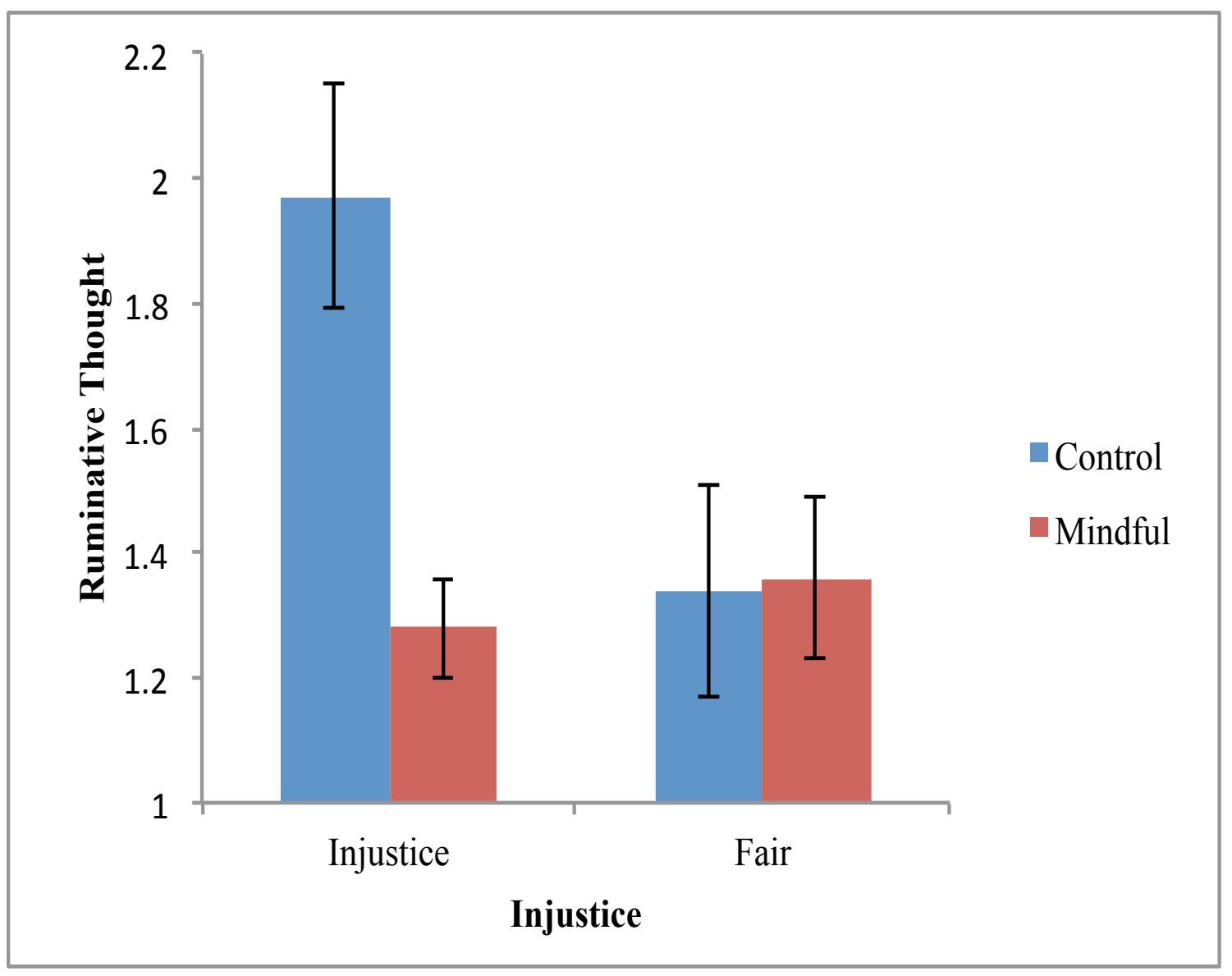

Note: Error Bars Represent Standard Error. 
Figure 3: Interactive effects of injustice and mindfulness on outward negative emotion (Sample 1)

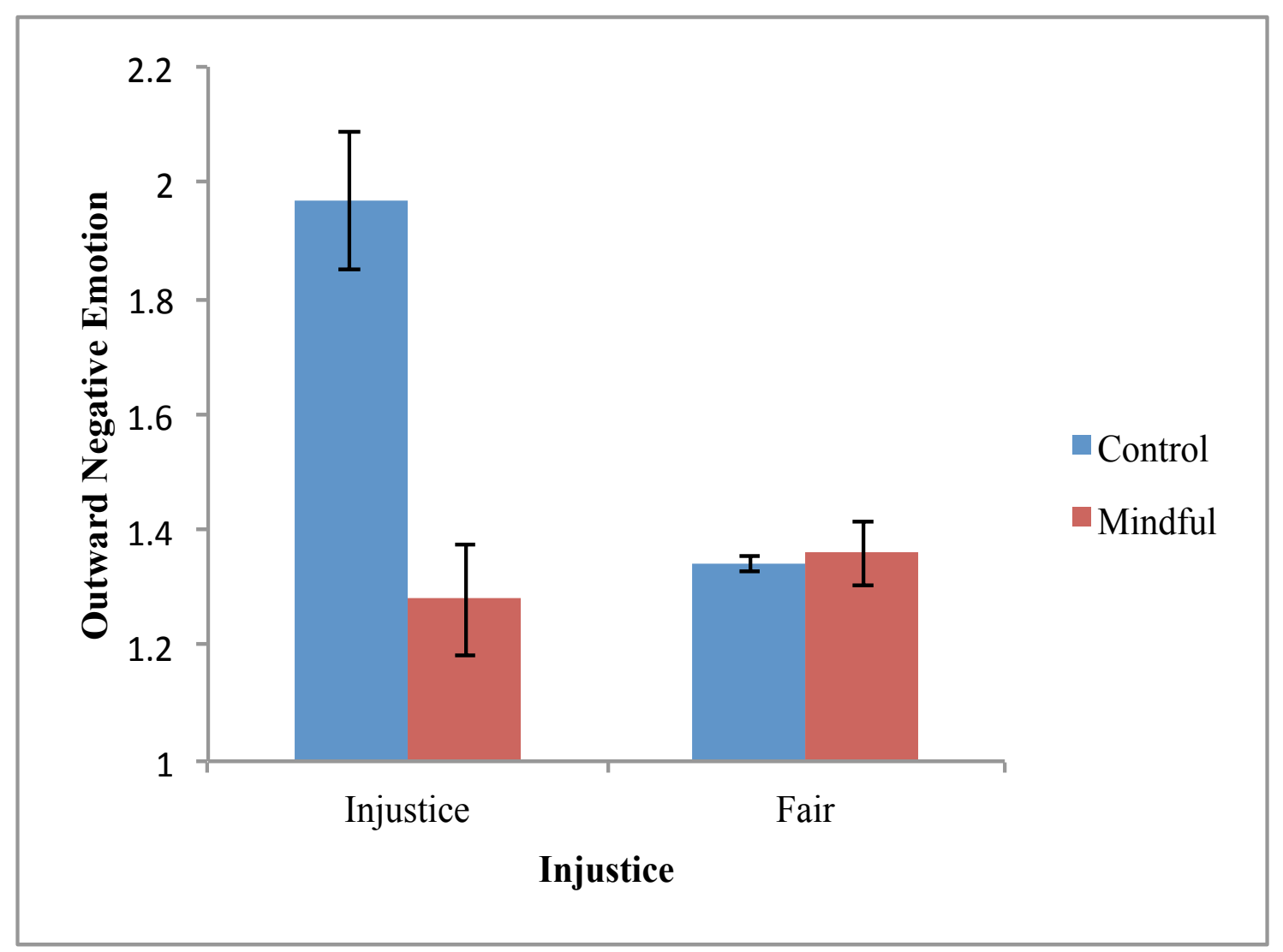

Note: Error Bars Represent Standard Error. 
Figure 4: Interactive effects of unfairness and trait mindfulness on ruminative thought (Sample 2)

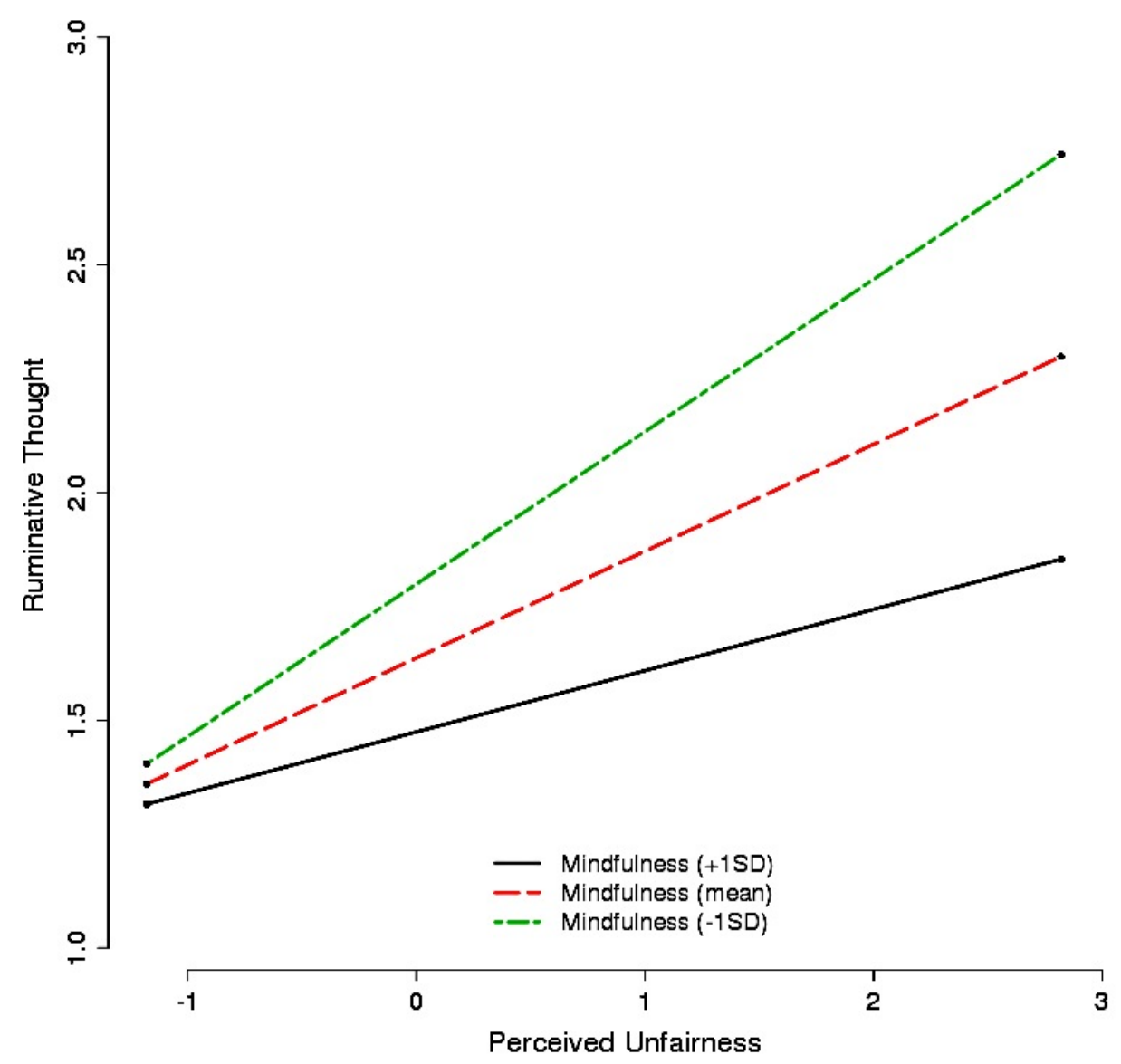

Note: Simple slopes plotted at +1 SD, mean, and -1 SD levels of mindfulness based on values of mean-centered predictors. 
Figure 5: Interactive effects of unfairness and trait mindfulness on anger (Sample 2)

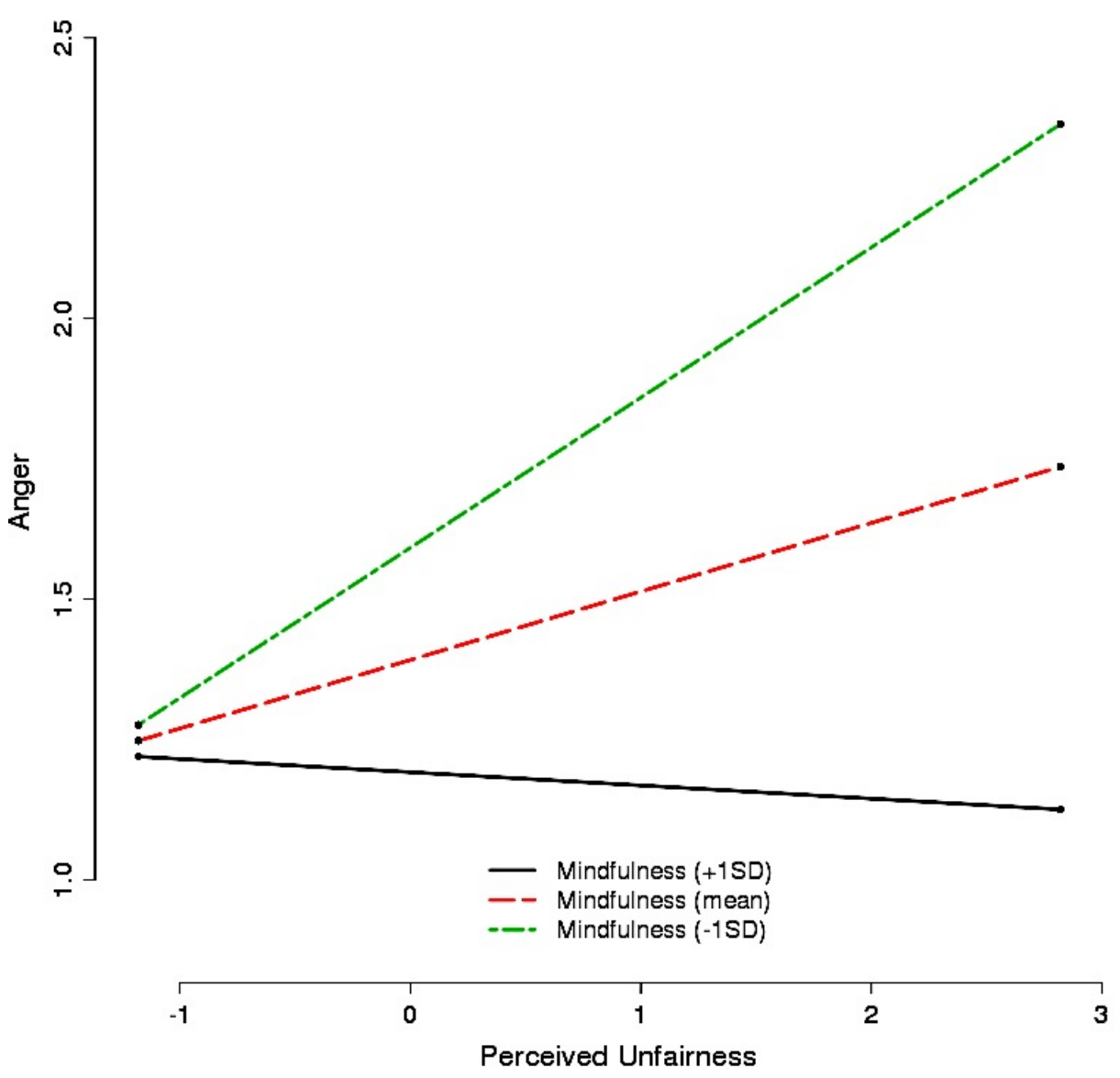

Note: Simple slopes plotted at +1 SD, mean, and -1 SD levels of mindfulness based on values of mean-centered predictors. 